\title{
Tiempos de pandemia. Percepciones de estudiantes de telesecundaria en el medio rural: los otros aprendizajes, las otras vivencias, las otras experiencias Times of Pandemic. Perceptions of Telesecondary Students in the Rural Area: The Other Learnings, the Other Experiences, the Other Practices
}

Enrique Pieck Gochicoa Universidad Iberoamericana Ciudad de México, México enrique.pieck@ibero.mx

... también me roba tiempo, pero gracias a eso aprendo algo que no aprendo en la escuela.

Mucho se ha escrito sobre la pandemia y sus implicaciones en el sistema educativo, sobre cómo el cierre de las escuelas ha significado afectaciones en la dinámica escolar, y en la vida y dinámica social de sus estudiantes. Ha sido más común preguntarnos sobre protocolos, incidencia en los niveles de aprendizaje, escenarios posibles cuando "termine" la pandemia, etc., que atender a las voces de los y las jóvenes para conocer cuál ha sido su percepción de esta situación y cómo ha afectado sus vidas. ${ }^{1}$ En este ejercicio narrativo, el foco han sido los y las jóvenes; interesaba conocer su perspectiva. Fue así como en pláticas con un docente de las telesecundarias vinculadas con la comunidad (TVC) en la sierra de Puebla (zona 016), surgió la idea de solicitar a sus estudiantes que escribieran sobre cómo se habían

\footnotetext{
${ }^{1}$ Las y los jóvenes son estudiantes de una telesecundaria rural en la comunidad de Tepexoxuca en la Sierra de Puebla. Para salvaguardar su confidencialidad, se han omitido sus nombres
} 
sentido en tiempos de pandemia, qué había sido lo más significativo. Esta iniciativa permitió contar con cerca de veinte relatos, en los que un grupo de jóvenes narra lo que fue su experiencia durante los meses de confinamiento en que se cerró la escuela. Los temas que más les importan se fueron haciendo presentes en las narraciones: las ganas de volver a la escuela, el reencuentro con la familia, las amistades, la añoranza de espacios de socialización, el aburrimiento, los quehaceres familiares, los nuevos aprendizajes, el trabajo, entre otros.

Para efectos de este análisis, ${ }^{2}$ resultó interesante cómo entre los temas que se hicieron presentes en los relatos, está el de los nuevos aprendizajes; es decir, la gama de saberes y habilidades que han adquirido los y las jóvenes al no estar en la escuela. Lo mismo llama la atención el recuento de las transiciones al mundo del trabajo que algunos y algunas adolescentes han tenido que vivir en este periodo. Esos dos temas nos resultan particularmente significativos y sobre ellos se prioriza el análisis. Algo que podemos destacar en este ejercicio es cómo los procesos de aprendizaje no se detienen al cerrar las escuelas, sino más bien se hacen presentes de diversa manera, sobre todo en un contexto rural, donde las actividades productivas son parte esencial del entorno. Pareciera que seguimos centrándonos en lo que se ha perdido en términos escolares desde el punto de vista del sistema. Seguimos enfocados en buscar los déficits y no entendemos lo que se ha ganado de alguna otra manera y que los jóvenes quieren y necesitan. Asimismo, imposible no atender a los rasgos sociales y económicos propios de espacios rurales marginales donde opera esta telesecundaria, ya que esto nos permite comprender las percepciones de los y las adolescentes y cómo significan este tiempo especial.

\section{La nostalgia de la escuela, las amistades}

Los relatos expresan los sentimientos de jóvenes al quedarse sin la posibilidad de seguir asistiendo a la escuela. Sus voces ofrecen la oportunidad de conocer cómo se sintió esta decisión, qué reper-

\footnotetext{
${ }^{2}$ Agradezco las observaciones recibidas por Luz María Moreno, Roxana Vicente y Constantino Gasca.
} 
cusiones tuvo, cómo se vivió esta etapa en un entorno rural, su nostalgia de la escuela, qué experiencias deja, las cosas nuevas que han aprendido, por dónde han ido sus reflexiones, cuáles fueron los principales retos. Comenta un estudiante: "No pude comprender algunos temas de la escuela; se me amontonan los trabajos de la casa. No es lo mismo aprender en casa que en la escuela, porque no hay un maestro que me corrija o me muestre cómo hacerlo".

Prácticamente todos echan de menos ir a clases, ver a las amistades, ir a hacer deporte: "y no puedo salir de mi casa a jugar básquet, ni ir a la cancha, no puedo salir a ningún lado". Otra joven menciona: "me aburría un poco ya que estaba acostumbrada a ir a la cancha a jugar básquet y a estar con mis amigas". Otra más señala: "la verdad quisiera ir o regresar a clases para poder convivir con mis amigas y amigos, también para tener tiempo para mí, como adolescente, y disfrutar las cosas, lugares, deportes, etc., y no pasarme encerrada en mi casa y hacer la misma rutina”.

Durante este tiempo, quienes tienen las condiciones para estar en clases vía virtual, expresan cómo no es lo mismo. Se les "hace más difícil que cuando el maestro estaba con nosotros dándonos clase en la escuela". Comenta un estudiante, "también es bueno buscar por mis medios sobre algunos temas, pero en algunos casos no entiendo y creo que me hace falta la ayuda de mi profesor".

Un sentimiento que atraviesa casi todos los relatos es la frustración y la tristeza por no poder regresar a clases, no ver a las amistades, no poder realizar convivios, fiestas de cumpleaños, entre otros. Más se acentúa este sentimiento cuando los y las jóvenes se van enterando de las falsas promesas sobre la fecha para volver a clases: "todo fue una mentira y no hubo regreso a clases, y me puse más triste y peor, porque en esa época hacíamos convivios de lo del día de muertos y la navidad, pero ese año no se pudo festejar nada de eso, y también lo malo que las posadas que se hacían, ya no se hicieron".

Se percibe el sentimiento de aburrimiento en sus casas. Uno de ellos expresa cómo se pone contento cuando el profesor empieza a invitarlos a pequeńas reuniones para no perder el estudio. Y otro agrega "lo mejor de esas reuniones es que ya puedo ver a mis compañeros y convivir un rato con ellos". 


\section{El entorno del hogar}

El deterioro de la situación económica desatada por la pandemia ha llevado a que muchas madres se hayan visto forzadas a trabajar fuera de casa. Éste es otro indicador de cómo la pandemia ha afectado fundamentalmente a las mujeres, dejando al descubierto desigualdades sociales que ya sabíamos, pero que la "supuesta" normalidad tenía escondidas. Lo que genera esta situación puede ser captado en el siguiente comentario:

Pero ya después por el tiempo me acostumbré. Veo a mi mamá cada quince días. Viene dos días. Esos días trato de estar con ella lo más que puedo. Yo quisiera que no se fuera, ya que cuando está ella, todo es... pero la falta de dinero es lo que hace que regrese al trabajo, pero eso me hace pensar que tengo que echarle ganas para que no todo el tiempo mi mamá trabaje... En estos días hemos estado trabajando, pintando, lijando y resanando. Estuvimos trabajando un mes, ya que eran 80 sillas y 20 mesas... y ahora estoy descansando un poco.

Algunas mamás han tenido que ir a buscar trabajo fuera y regresan hasta tarde-noche, eso lleva a que las y los jóvenes se vean obligadas a sortear el día sin su presencia. Comenta: "mi mamá se tuvo que ir a trabajar y yo tenía que hacer la mayoría de las cosas, ya que mi hermana estudia en la universidad y tenía muchas clases. Ya no salía y extrañaba mucho a mi mamá". Para algunas madres, buscar trabajo ha representado todo un cambio en sus vidas al tener que ausentarse y delegar a sus hijos o hijas una serie de actividades hogareñas. Esta situación es una resultante de la pandemia y de cómo ha afectado la situación económica y la dinámica de muchas familias en el medio rural.\}

Se percibe también un proceso de revaloración del estar en casa: "bueno, al principio la cuarentena y no me gustó, ya que no estaba acostumbrada a estar en mi casa, pero me gusta porque así estoy más con mis papás y mis hermanos", Otro joven comenta: "puedo tener más tiempo para mí". A pesar de eso, hay quien comenta sobre el incremento de las tareas domésticas desde que no asisten a clase: 
"me encargan a mi sobrina y es muy traviesa. Sacar los chivos de mi abuelita, que cuando no quiero salir, me obligan”.

\section{Los otros aprendizajes}

Se evidencia en los relatos el reconocimiento que los y las jóvenes hacen de que en ese año de pandemia aprendieron otras cosas. Son aprendizajes que se ubican más en el ámbito informal, no formal y en el aprender-haciendo, más vinculados con la vida cotidiana, con el trabajo local, con las actividades de la familia, con las costumbres, con el entorno cultural de los espacios. Como señala un compañero al constatar que no fue cierto que iban a volver a clases tan pronto como hubieran querido: "lo bueno de ese año es que aprendí muchas cosas, como por ejemplo, a manejar. No manejo del todo bien, pero algo aprendî”. Otro estudiante igual, recuerda cómo aprendió a plantar árboles y flores, lo mismo que una joven menciona que en esos meses aprendió a construir cometas y a volarlas. Los aprendizajes son muy diversos y refieren a múltiples actividades de todo género.

$\mathrm{Al}$ reflexionar sobre las cosas buenas durante ese año, es común que las y los jóvenes comenten sobre cosas que aprendieron: "aprendí cosas artesanales, conocí lo que hacen mis papás cuando yo iba a la escuela. Conocí pueblos que no conocía, conviví más con mi hermano, pude visitar a mis abuelitos. En la familia he convivido con ellos, ir con ellos a conocer más de mis familiares, que yo no conocía”.

Las y los jóvenes terminan participando en muy diferentes actividades, a veces vinculados con sus familias y otras con conocidos: "empecé a trabajar con mi madrina en los tacos de carnitas, empecé a aprender a hacerlos... aprendí muchas cosas en abril”.

Al no poder socializar con amistades, hay quienes se han incorporado a las actividades familiares. Comenta una estudiante: "ya en mi casa, ayudarle a mi mamá, le ayudamos a sembrar el terreno, a mis hermanos a hacer la tarea, también fui a sembrar mis rábanos, a traer leña y muchas cosas más..., aprendí a deshojar”. De esas pequeñas incursiones es donde empiezan a surgir otros aprendizajes -otros saberes- diferentes de lo que se aprende en la escuela y que se 
ubican más en el ámbito de los aprendizajes a lo largo de la vida. Son fruto de procesos de aprendizaje situado -un aprender-haciendo-, donde el o la joven se "pegan" a familiares y conocidos en las actividades y oficios que practican. La participación de los y las adolescentes en estas nuevas actividades habla de la importancia de estos saberes de frente al conocimiento escolarizado, fundamentalmente en términos de su utilidad en este tipo de contextos.

Es común que las y los estudiantes, ante la ausencia de la escuela, terminen incorporándose a las actividades propias del hogar en el medio rural, tal como señala una joven: "aprendí a sembrar cebollas, jitomate y ajo. Cuando estaba trabajando en sembrar cebolla salí muy cansada, y al siguiente día igual, había que ir a sembrar cebolla, pero ya nos faltaba poco. Terminamos de una y fuimos a sembrar jitomate en un invernadero".

Para algunos éste ha sido un tiempo que les ha permitido reflexionar y reencontrarse con espacios cotidianos: "empecé a saber más de mi familia, sobre qué hacen cuando yo no estoy, cómo se divierten y ahora lo hacen conmigo". Entre otros aprendizajes que reportan, están los que se vinculan con el entorno del hogar: "que aprendí a hacer muchas cosas, como a hacer la comida, a hacer pays, pasteles, galletas, gelatinas de flor de rosa”, parecido a otra niña que comenta cómo "en este tiempo aprendí a cocinar huevo, sopa, arroz, caldo de pollo". Es interesante cómo estas habilidades culinarias son referidas como nuevos aprendizajes de este periodo de tiempo. Otra joven menciona que en sus tiempos libres aprendió a componer canciones y también a escribirlas. Para otra estudiante, sus aprendizajes vienen de "haber aprendido a bailar, cumbia, norteña, banda, pero lo que más me gusta fue que aprendí danza y a hacer bocetos de moda”. Esto nos hace pensar en los retos que presentan las escuelas como lugares que posibiliten conocer y valorar las actividades familiares y comunitarias, y también sobre el conocimiento de uno mismo.

Hay quienes durante la pandemia aprendieron una actividad artesanal, como producir mezcal, o ya bien la confección de artesanías de ocoxal. "También aprendí a trabajar en el campo, a crear o hacer abono de diferentes maneras, cómo cuidar plantas frutales". Entre tantas actividades, expone que era un reto hacer sus tareas y atender labores domésticas... como que se va dejando de cumplir tareas. 
Finalmente, y en otro tipo de aprendizajes, hay quienes en sus evocaciones rescatan haber aprendido "que el estudio es muy importante y tengo que valorarlo, aprender que uno debe controlarse cuando hay un problema y no desesperarse”. Continúa, "también en mi casa aprendí a cuidar mejor a los animales, que si comen algo que no es o les pica un animal venenoso. Pero también me roba tiempo, pero gracias a eso aprendo algo que no aprendo en la escuela”.

\section{Transición al mundo del trabajo}

Resulta interesante cómo para algunos adolescentes, el hecho de no ir a la escuela los ha ido moviendo a espacios donde dan sus primeros pasos en el mundo del trabajo, a tener sus primeras inserciones realizando diferentes tareas. Una estudiante comenta: "me llevaron a trabajar al campo y gané mi primer sueldo y aprendí a trabajar en el monte, a lo que se dedican mis hermanos. Aprendí a descargar madera y fue un trabajo difícil y no tan fácil, pero con el tiempo aprendí cómo trabajar para ganar mi sueldo".

Las condiciones de los trabajos resultan a veces retadoras para las y los jóvenes, quienes al no poder ir a la escuela, terminan participando en actividades familiares propias del medio rural:

cuando acabamos de trabajar, caminas tanto que mis pies me dolían, mi cintura está adolorida... tal vez era la primera vez que trabajaba en el campo. Pero no me rendí a pesar de que la dońita pensaba que yo no podía trabajar. Gracias a Dios no me dejó caer ante esta situación... como tres semanas trabajando no es tan fácil como se ve, y tampoco es fácil ganarse el dinero, el sustento... y seguimos trabajando.

Hay comentarios que evidencian las primeras transiciones al mundo laboral que muchos y muchas adolescentes tuvieron durante esos meses. Representa un brinco "forzado" por las circunstancias que empieza a evidenciar el paulatino alejamiento de la escuela. Constituyen posibles puntos de quiebre en sus trayectorias de vida, cuando hay el riesgo del abandono de los estudios. Como señala uno de ellos: "volvieron las tareas, pero para mí ya era aburrido porque 
pensaba que esas tareas ya no tenían ningún propósito y empecé a dejar de interesarme en el estudio y la escuela, pero tenía que continuar haciéndolo por mi propio bien".

Otro testimonio da cuenta de la diversidad de actividades en que se involucraron las y los estudiantes durante esta etapa, muchas de éstas apoyando las actividades productivas de los padres: "ya después de un tiempo trabajé dando clases a una abuelita muy linda. Y, pues, casi no salía de casa. Mi mamá trabajaba en un cultivo de fresas, así que sólo la veía en la noche y mi papá hace muebles. Mis hermanos y yo le ayudamos a lijar y a pintar".

Los y las jóvenes terminan involucrándose en actividades a veces pesadas, resultado de procesos de resiliencia que se viven en estos contextos:

y ya cuando yo trabajé, mis hermanos me llevaron al monte a cargar madera... regresamos algo tarde y comimos y me fui a dormir porque ya me había cansado y cuando estuve en casa me puse a chapear para que no hubiera serpientes. Tiempo después volvimos a trabajar con doña Paulina... otra vez talachada y limpiar el terreno.

En estas circunstancias, hay quienes en sus reflexiones expresan agradecimiento por todo lo que tienen a pesar de la pandemia: "Gracias a Dios, tengo trabajo y salud para trabajar y salir adelante".

El ejemplo de otro estudiante es muy elocuente de los cambios en la dinámica diaria que muchos jóvenes tuvieron que realizar por motivo de la pandemia. Habla de su experiencia laboral como resultado de no poder ir a la escuela:

fui a trabajar por primera vez. Me invitaron a rascar una fosa con mi papá. La primera vez me sentí cansado, sólo fuimos por un rato en la mańana. La fosa que rascamos estaba muy suave, así fuimos avanzando... desde ese día empecé a trabajar con los del agua. Empecé a comprarme mis cosas, a ayudar en mi casa. Le daba a mi mamá para el recaudo o lo que se necesitaba. Así, empecé a comprarme cosas, para mí y a mis hermanas. Así fue la rutina de todos los días: llegaba a mi casa a bańarme y a dormir, porque todos los 
días salía temprano de casa, salía a las 5:30 de la mañana. Todos los días eran cansados, lo cual no podía hacer otra cosa. En enero de 2021 empecé con nuevas expectativas para seguir adelante. Después ayudaba a mis papás con la siembra que tenían, de cebolla. La cosechamos en febrero, salieron algo grandes. La vendimos por kilo, fuimos a ranchear a Temextla... después inició junio, fue algo maravilloso. Hice un negocio que me benefició después. Todos los días era trabajo hasta el día de hoy. Esa fue lo que viví en este año que no hubo clase.

En la misma línea otro joven comenta:

A los principios de ese año empecé a ir a trabajar a casas ajenas. Yo ya quería ganar mi propio dinero y por eso lo hice y busqué trabajo, pero no quería ir solo, así que invite a unos de mis compañeros, más que mi compañero es mi amigo, entonces aceptó ir a trabajar y fuimos, y estuvo bien, porque así, en el trabajo, porque tenía con quien hablar y desde ese día empecé a trabajar en casas ajenas, porque se siente muy bien ganar y gastar tu propio dinero sin pedirle prestado a nadie.

Estos testimonios son muy elocuentes del significado que tiene el trabajo en las vidas de estos jóvenes, lo que significa que tengan sus propios ingresos en esos contextos. En cierta forma, estas incursiones son el resultado de la situación económica de sus familias, de la importancia de estos espacios ante el cierre de las escuelas debido a la pandemia. Es así como la suspensión de clases lleva a algunos y a algunas a incursionar en el mundo del trabajo. Nuevas actividades generan nuevos aprendizajes, nuevos saberes y habilidades que guardan un estrecho vínculo con las posibilidades y necesidades de estos contextos rurales. Implica un paso a la adultez, proceso muy visible en muchos contextos donde se evidencia la incorporación temprana de los jóvenes al mundo del trabajo. Éste es el testimonio de un estudiante:

Después me dejó mi papá con don Julián a terminar la fosa. Al poco tiempo me ofrecieron trabajo... me pusieron a atender a los 
animales, les di de comer a los borregos y a las gallinas después. Trabajé todos los días hasta el mes de mayo de 2020, desde ese día trabajé con Don Celerino. La primera vez no aguantaba, se me hizo muy cansado ese día. No pude dormir toda la noche por el cansancio. Al otro día no fui a trabajar porque no podía pararme. Tomé una pastilla y poco a poco me fui sintiendo mejor que ese día terrible, porque no podía hacer nada... poco a poco me fui acostumbrando a pararme temprano. Desde ese día aprendí a valerme por mí mismo.

Muchos de estos testimonios son muy elocuentes de la actitud resiliente que se muestra en los procesos de inserción laboral de las y los adolescentes de telesecundarias rurales. Se trata de inserciones que muchas de ellas se caracterizan por ser trabajo pesado: cavar fosas, cosecha de hortalizas, limpiar caminos, jornadas largas, entre otras. No en balde constatar el cansancio con el que regresan a sus casas después de una jornada larga. Interesante observar en los relatos, cómo estas ocupaciones constituyen el inicio de sus trayectorias laborales, entreveradas con sus itinerarios educativos. Ante el cierre de escuelas y como una forma de hacer frente a las necesidades económicas, algunos y algunas jóvenes se ven en la necesidad de incorporarse en algunas de las posibilidades de trabajo que ofrecen estos contextos. Esto se manifiesta desde la típica ayuda a los padres (en la agricultura, en los oficios), hasta la vinculación con un sinfín de pequeñas actividades que se presentan en la comunidad y en las cuales se pueden involucrar.

A la par del significado que les representa trabajar (entre otras, poder allegarse de un sustento), son de destacar las diferentes habilidades que los y las jóvenes adquieren en estos pequeños trabajos. Van desde el aprendizaje de habilidades técnicas, propias de la actividad que realizan (como aprender a lijar y barnizar, cuidar de los animales, cavar una fosa), hasta habilidades más del tipo socioemocional y laboral, tales como formarse en actitudes de disciplina, responsabilidad, solidaridad, entre otros. Eso habla del carácter formativo que tienen estas pequeńas incursiones en el mundo del trabajo a esta edad. Vaya como ejemplo el del joven que invitó a un amigo a chambear, y que para ello ahorró para comprarse su bici y 
así pedalear 40 minutos -junto con su amigo- para llegar diario al lugar donde consiguió trabajo. Son jóvenes que "se abren mundo" en los diferentes trabajos que se presentan en el medio rural.

No hay que olvidar, sin embargo, que en este caso se trata de trabajos sencillos, manuales, donde no se requieren grados educativos para ejercerlos; son actividades que se ubican, en su mayoría, en el sector informal. Este hecho habla, de inicio, sobre los espacios de trabajo a los que se incorporan los y las jóvenes en estas etapas de sus vidas. De alguna forma, refiere a una dinámica en la que se encuentra la mayoría de los y las jóvenes de sectores vulnerables donde, debido a situaciones económicas y familiares, se ven obligados a abandonar sus estudios y a transitar al mundo del trabajo. Este tipo de inserciones son las que van definiendo desde ya sus posibles trayectorias, donde se van acumulando ventajas y desventajas.

Como reflexión última, es preciso notar cómo en los relatos se hace presente una amplia gama de situaciones que son el trasfondo de este vivir en comunidad y que resultan referentes obligados para los y las jóvenes en sus narraciones... son parte de la vida diaria. Entre ellas están: las actividades productivas propias del medio rural (sacar a los animales, sembrar hortalizas, preparar los terrenos para la siembra), las festividades, las relaciones entre la comunidad, los paseos de novios y novias, las actividades sociales y deportivas con las amistades, la sensación de aburrimiento en estos tiempos de pandemia, las restricciones de movilidad, la muerte y sepelio de parientes, colaborar en la decoración de la capilla, las enfermedades, la ida al médico, las salidas a saludar a los familiares de otros pueblos, la valoración del entorno familiar, las salidas a conocer otros pueblos, entre tantas otras. Éste conforma el acontecer comunitario del cual participan los jóvenes, más intensamente ahora, en tiempos de pandemia. Termina como un rencuentro de los y las jóvenes con una dinámica comunitaria que ahí está y que implica ser parte de un sinfín de actividades. De alguna manera, evidencia cómo la escuela nos ha desvinculado de estas formas de vivir en comunidad y que nos tendrían que hacer pensar en términos más orgánicos, entre conocimientos, habilidades para el trabajo y ejercicio de la vida comunitaria. 